\title{
KULTURNEAKTIVNOSTI SRBIJEUEVROPIISVETU:
} $2000-2010$.

Sažetak: Uvodni deo teksta predstavlja osvrt na relevantnost kulturnih vrednosti i kulturnih odnosa u kontekstu izmenjenog globalnog okruženja i aktera u međunarodnoj areni. Posebno se ističe značaj kvaliteta sadržaja i narativa u efektivnim kulturnim odnosima. ${ }^{1}$ U tekstu se dalje podvlače društveno-politički aspekti koji su uticali na oblikovanje kulturnog razvoja Srbije na početku XXI veka. Pregled osnovnih rezultata istraživanja „, Kulturne aktivnosti Srbije u Evropi i svetu 2000 - 2010. “ cini glavni deo teksta i predstavlja doprinos široj analizi međunarodnih kulturnih odnosa Srbije. Istraživačka pitanja vezana su za sadržaj kulturnih aktivnosti Srbije, zatim za ideje, vrednosti $i$ narative, $i$ konačno za principe i prioritete kulturne politike $u$ kontekstu međunarodnih kulturnih odnosa.

Ključne reči: Srbija, kulturna politika, međunarodni kulturni odnosi, kulturni obrazac, kulturni program

Porast javne svesti o značaju kulture na početku 21. veka jasan je pokazatelj promena u konstelaciji odnosa koji imaju transnacionalni predznak. ${ }^{2}$ Može se reći da danas kultura jednako predstavlja i način izražavanja identiteta $\mathrm{i}$ moći, kao i izgrađenih odnosa i razumevanja sa drugima. Međutim, vrednost kulturnih aktivnosti dolazi upravo od

1 Ovaj tekst je nastao u okviru rada na naučnom projektu Ministarstva za nauku i tehnološki razvoj Republike Srbije (br. 149004), i predstavlja deo istraživanja za doktorsku disertaciju ,Međunarodni kulturni odnosi i interkulturna komunikacija u funkciji (re) pozicioniranja Srbije u evropskoj i svetskoj javnosti“.

2 Rasprave o kulturnoj politici u diskursima Evropske unije, kao deo pokušaja novog osmišljavanja Evrope i kulturne konfiguracije evropskog prostora, iznedrile su i nove transnacionale tokove, koji naglašavaju relevantnost kulture. Više u: Majnhof U.H., Triandafilidu A. (prir.), Transkulturna Evropa, CLIO, Beograd 2008. 
činjenice da kultura predstavlja i povezuje ljude i narode, pre nego isključivo vlade ili političke pozicije. Tako se više gotovo ne može govoriti o statičnoj ,kulturnoj reprezentaciji“, već je potrebno pružiti odgovore u kontekstu umnoženog sadržaja i međunarodne konkurencije, kao i omogućiti masovnom stanovništvu da razvije vitalne sposobnosti kulturne pismenosti. Dakle, kulturni sektor, od velikih nacionalnih institucija sve do malih nevladinih i amaterskih organizacija, ima odgovornost medijacije i prevencije od kulturnih ponora putem izgradnje kulturnih mostova.

Menadžment međunarodnih kulturnih odnosa je po svim merilima krupan zadatak, koji zahteva kombinaciju vizije, autoriteta, konsenzusa, kreativnosti i organizacionih sposobnosti. Kvalitet sadržaja predstavlja najveći deo efektivnih kulturnih odnosa. Samo smisleni narativi i vizije budućnosti mogu biti održivi u dugoročnom kontekstu. Ti narativi treba da sadrže odgovore na pitanja: Šta zaista predstavljaju određena zemlja i njen narod? Za koje vrednosti se oni zalažu? Odnosno, koja dostignuća kulturne baštine i savremene kulture mogu poslužiti za formulisanje kulturnog obrasca ${ }^{3}$ zemlje? A, ,sve prave vrednosti istovremeno su i vrednosti kulture kako god da shvatamo kulturu. "“4 Konačno, reč je o takvom mišljenju koje se ,zasniva na širem društvenom osećanju značaja i misije kulture, na postojanju 'opšteg mišljenja' o njenom 'prosvetiteljskom' karakteru. “5 Kada se govori o promeni vrednosti u ovom kontekstu, radi se o promeni kulturnih praksi, a posebno u kontekstu programiranja kulturnih aktivnosti (programske politike).

Tokom poslednje decenije XX veka, ,zatvorena i izolovana Srbija poništila je sve elemente ranije otvorenosti (Jugoslavije) i međukulturne komunikacije sa svetom i susedima i sve se više okretala uskoj odbrani 'nacionalnih in-

3 Kulturni obrazac se poima kao „smisaoni okvir orijentacije i integracije jedne zajednice koji obuhvata, pre svega, vrednosne sisteme pomoću kojih pojedinci i društvene grupe dolaze do razumevanja sebe i sveta u kome žive, kao i modele za akciju radi ostvarivanja izabranih ciljeva i promovisanja poželjnog načina života" Golubović Z., „Kulture u tranziciji u Istočnoj Evropi i Jugoslaviji: raskorak između kulturnog i nacionalnog obrasca“, u: Kulture u tranziciji, Plato, Beograd 1994, str. 35.

4 Božović R., Život kulture, „Filip Višnjić“, Beograd 2009, str. 29.

5 Dragićević Šešić M., „Demokratičnost i dometi kulturne politike“, Zbornik Fakulteta dramskih umetnosti, br. 8-9, Beograd 20042005, str. 387-397. 
teresa' i ciljeva koji su u stvari bili kontraproduktivni."“6 Kao rezultat, nastale su prakse instrumentalizacije kulture, koje su u određenoj meri nastavljene i posle 2000. godine. „Odbacivanjem dogmatsko-prosvetiteljskog kulturnog obrasca, koji je na ovom prostoru dominirao do poslednje decenije XX veka, došlo je do formiranja tzv. tranzicionog obrasca (ili kulturne matrice), sa specifičnim hibridnim elementima nacionalnog i mondijalističkog. “7 Tako je, u suštini, došlo do sužavanja polja kulturnog delovanja, odnosno do marginalizacije kulture, kako u zemlji tako i u aktivnostima Srbije u Evropi i svetu. ${ }^{8}$

U okolnostima turbulentnih procesa evropskih integracija, Srbija ostaje pred izazovima u odnosu na sopstveni društveno-politički i kulturološki okvir, kao i pred konceptima vezanim za identitet, a koji bi ispunili taj okvir. Time se otvara i niz nedoumica o pravcima kulturnog razvoja Srbije, uz kritičko preispitivanje i usvajanje ostvarenja kulturne tradicije i savremene kulture.

Uzimajući u obzir raznolikost pristupa međunarodnim kulturnim odnosima, ${ }^{9}$ na primeru kulturnih aktivnosti Srbije u Evropi i svetu, analiziraćemo postojeće koncepte i elemente kulturne politike, ${ }^{10} \mathrm{u}$ prilog izazovu traganja za efektivnom ravnotežom u odnosima između kulture, države i politike.

6 Golubović Z., Pouke i dileme minulog veka, „Filip Višnjić“, Beograd 2006, str. 237.

7 Rogač Lj., „Kulturna dijagnostika identiteta i imidža Srbije u evropskom kontekstu“, u: Kultura, br. 122/123, Beograd 2009, str. 120-140.

8 Razmatrajući dominantne trendove u oblasti kulturne politike Srbije, Vesna Đukić jasno definiše period kraja XX veka kao „blokiranu tranziciju“, odnosno period diskontinuiteta u oblasti kulture. Više u: Đukić Dojčinović V., Tranzicione kulturne politike - konfuzije i dileme, Zadužbina Andrejević, Beograd 2003.

9 Termin „međunarodni kulturni odnosi“ koristimo kao najširi pojam, koji je u praksi zastupljen u najvećoj meri, dok se u literaturi još govori o „,međunarodnoj kulturnoj politici“, „kulturnoj diplomatiji“, „međunarodnoj kulturnoj saradnji“ i sl. Vidi: Vizomirski Dž. M., Šnajder P. S., Kulturna diplomatija, Balkankult fondacija, Beograd 2006.

10 Vidi: Đukić V., Država i kultura - studije savremene kulturne politike, Institut za pozorište, radio i televiziju, Fakultet dramskih umetnosti, Beograd 2010. Posebno je značajno četvrto poglavlje o razvojnim mogućnostima savremene kulturne politike u Srbiji. 


\section{Istraživanje Kulturne aktivnosti Srbije u Evropi i svetu 2000 - 2010.}

Predmet ovog istraživanja jesu kulturne aktivnosti Srbije u Evropi i svetu u periodu od 2000. do 2010. godine. Pozorišne predstave, projekcije filmova, koncerti, izložbe, književne večeri, festivali i manifestacije čine kulturne programe putem kojih je Srbija realizovala deo međunarodne kulturne saradnje, odnosno značajan aspekt međunarodnih kulturnih odnosa. Polazeći od pretpostavke da su ciljevi ovih kulturnih aktivnosti Srbije predstavljanje zemlje, promocija kulturnih vrednosti, uspostavljanje dijaloga sa određenom sredinom zemlje domaćina, poboljšanje reputacije i imidža zemlje i naroda, itd., potvrđuje se relevantnost ove vrste kulturnog delovanja. Obim, tip, sadržaj i narativi ovih kulturnih programa trebalo bi da imaju uticaja na stvaranje ukupnih predstava i slika o Srbiji, šire od isključivo kulturnog konteksta.

\section{Istraživačka pitanja}

Osnovna istraživačka pitanja vezana su za sam sadržaj kulturnih aktivnosti Srbije. Šta je obuhvaćeno tim sadržajem? Kakvi su struktura i intenzitet kulturnih aktivnosti i programa Srbije u odnosu na faktore vremena i mesta realizacije? Takođe, u vezi sa tim su ideje, vrednosti i narativi, kao okosnica ovih programa. Koji su dominantni narativi ovih kulturnih programa? Postoje li alternativni narativi? Ukratko, šta Srbija kroz različite kulturne forme predstavlja evropskoj i svetskoj javnosti?

Ostala pitanja vezana su za principe i prioritete kulturne politike u kontekstu međunarodnih kulturnih odnosa. Da li postoje uspostavljeni mehanizmi kreiranja kulturnih aktivnosti Srbije u inostranstvu? Koji su dometi i efekti tih aktivnosti, posebno u odnosu na kulturnu politiku i njene prioritete? U kakvom su odnosu ovi kulturni pro-

grami prema postojećoj kulturnoj matrici Srbije?

Konačno, kao deo ishodišta isrtaživanja razmatraće se pitanja o predstavama i slikama Srbije koje se formiraju kao posledica ovih kulturnih aktivnosti, a koje se vezuju na postojeće percepcije imidža i identiteta zemlje, naroda i kulture. 


\section{Metodologija istraživanja}

Istraživanje „Kulturne aktivnosti Srbije u Evropi i svetu 2000 - 2010.“ predstavlja deo šireg istraživanja u oblasti međunarodnih kulturnih odnosa Srbije, iz perspektive kulturne politike i menadžmenta u kulturi. Stoga je i pristup ovom istraživanju u osnovi interdisciplinarni.

Osnovna tehnika koja je primenjena u ovom istraživanju je analiza sadržaja, kao „objektivno, sistematsko i kvantitativno opisivanje manifestnog sadržaja komunikacije“. ${ }^{11}$

U konkretnom slučaju ovog istraživanja, to se pre svega odnosi na preciznost u određivanju kategorija, zatim na relevantnost kategorija u ispitivanju sadržaja i konačno, na ravnotežu u pogledu kvalitativne i kvantitativne dimenzije analize. Analiza značenja nužno otvara mogućnost različitih tumačenja, kako u smislu sadržaja poruke, tako i samog pošiljaoca.

Izvor materijala za istraživanje bila su dokumenta Ministarstva spoljnih poslova Srbije i Ministarstva kulture Srbije. Istraživački uzorak predstavljaju godišnji izveštaji ovih ministarstava o saradnji Srbije sa svetom u oblasti kulture, a u kojima se navode realizovani kulturni programi. U uzorak su, dakle, ušli oni sadržaji koji su bili inicirani i/ili podržani od strane ovih ministarstava (oko 2400 programa). Mnogi sadržaji popularne kulture, estrade i drugi komercijalni sadržaji, koji nisu imali institucionalnu podršku, nisu zabeleženi u pomenutim dokumentima, pa tako nisu ušli ni u istraživački uzorak.

Osnovna jedinica analize je kulturni program, odnosno oblik difuzije kulture, koji je $\mathrm{u}$ formi opisnog tekstualnog zapisa. Tako definisana jedinica analize sadrži nekoliko komponenti: nosioce značenja - naziv, oblik i tip kulturnog programa, godina i zemlja realizacije, autor / inicijator programa, kao i informacije o povodu, uspešnosti, publici programa - koji su u funkciji ilustracije.

Analizom su obuhvaćene formalne i sadržinske kategorije. Formalne kategorije odnose se na zastupljenost kulturnih programa prema godini realizacije, na broj programa prema zemlji realizacije i na zastupljenost programa prema obliku kulturnih programa. Sadržinski i većinski deo analize tretira pojedinačne kulturne programe, njihove tipove i njihove dominantne narative.

$\mathrm{U}$ istraživanju je primenjena tipologija kulturnih programa koja je adaptirana prema oblicima difuzije kulture

11 Berelson B., Content Analysis in Communication Research, Hafner Publishing Company, New York 1971, str.15. 
i projekata u kulturi. ${ }^{12} \mathrm{U}$ tom smislu, definisano je šest grupa osnovnih oblika kulturnih programa, kao i njihovi tipovi:

I Izložbe: umetničke, kulturološko-dokumentarne, propagandno-animacione;

II Scenski programi: predstava, koncert;

III Filmski programi;

IV Književni programi;

V Manifestacije;

VI Konferencije. Protokolarni programi.

\section{Pregled osnovnih rezultata istraživanja}

Hronološki presek zastupljenosti kulturnih programa (Grafikon 1) pokazuje kakva je bila dinamika kulturnih aktivnosti Srbije u Evropi i svetu u najširem smislu. Prema ovim podacima, najmanja zastupljenost programa, svega $1 \%$, bila je u 2000 . godini, dok je najveći procenat programa koji su realizovani bio tokom 2007. godine, i što čini čak $17 \%$ ukupnog broja programa. Interesantan je i podatak o kontinuiranom opadanju zastupljenosti kulturnih programa od iste godine, koji je nastavljen i u 2010. godini. Prateći ove podatke, moguće je podvući paralelu sa hronologijom društveno-političkih zbivanja u Srbiji i svetu u protekloj deceniji. Kraj 2000. godine nagovestio je početak demokratskih promena u Srbiji, dok je 2003. označila povratak Srbije u međunarodne institucije i obnavljanje sporazuma o međunarodnoj saradnji. Te godine se beleži i nešto značajnija zastupljenost kulturnih programa (7\%), koja će nastaviti pozitivan rast u narednih pet godina. Od 2005. je putem odluka i dokumenata Vlade Srbije i formalno potvrđen politički kurs evropskih integracija Srbije, što je uticalo i na aktivnosti u oblasti kulturne saradnje. ${ }^{13}$ Međutim, ovaj optimizam je kratko trajao, s obzirom da je već 2008. godina svetske ekonomske krize označila i eliminisanje međunarodne kulturne saradnje sa liste aktivnosti od značaja za Vladu. ${ }^{14}$

12 Detaljnu podelu oblika i tipova projekata u kulturi vidi u: Dragićević Šešić M. Stojković B., Kultura menadžment animacija marketing, CLIO, Beograd 2007.

13 Tako je odsek u Ministarstvu kulture dobio u svom nazivu ,evropske integracije i međunarodna saradnja“.

14 To je i formalno potvrđeno ukidanjem odseka za evropske integracije i međunarodnu saradnju pri Ministarstvu kulture i njegovo svođenje na odeljenje za međunarodnu saradnju. Isto se odnosi i na 


\section{LJILJANA ROGAČ}

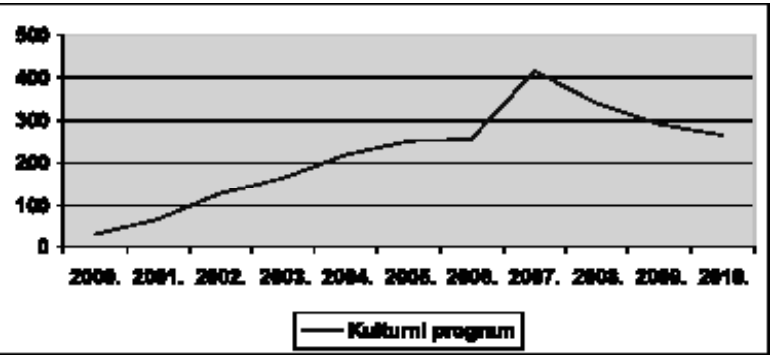

\section{Grafikon 1: Hronološki presek zastupljenosti kulturnih programa}

Analiza zastupljenosti kulturnih programa u odnosu na godinu realizacije ukazuje na opšti utisak da su kulturne aktivnosti Srbije u Evropi i svetu uslovljene, kako događaji iz bliže istorije pokazuju, pre svega unutarpolitičkim događajima, pa i dnevnopolitičkim i stranačkim previranjima.

U kontekstu evropskih integracija, spoljnopolitički prioriteti Srbije usmereni su ka zemljama Evropske unije i ka regionu Zapadnog Balkana. Za međunarodne kulturne odnose Srbije, relevantan je još i nivo saradnje vezan za tradicionalne veze sa određenim zemljama. U tom smislu, pregled kulturnih aktivnosti i programa Srbije ( $\mathrm{Ta}$ bela 1), u odnosu na zemlju u kojoj su realizovani, pruža uvid vezan za intenzitet međunarodne kulturne saradnje. Jedina zemlja u kojoj Srbija ima svoj zvanični kulturnoinformativni centar (KIC) jeste Francuska, pa je u KIC-u u Parizu zabeležen i najveći broj kulturnih programa (oko $12 \%$ svih programa). Od ostalih zemalja Evropske unije, Srbija je najviše kulturnih aktivnosti imala u Austriji, Italiji, Nemačkoj i Grčkoj (što zajedno čini oko 23\% svih programa). Od zemalja sa tradicionalno dobrim odnosima, najintenzivnije aktivnosti bile su u Ruskoj Federaciji (oko $4 \%$ ). U regionu, najviše kulturnih aktivnosti Srbija je zabeležila u Hrvatskoj (oko 4\%), dok u zemljama Zapadnog Balkana (bivša Jugoslavija bez Slovenije, i Albanija) ukupno obuhvata oko 10\% svih realizovanih programa. Kulturne aktivnosti Srbije u ostalim zemljama sveta najintenzivnije su u Severnoj Americi (oko 7\%), gde je i najveća srpska dijaspora. Značajna je i saradnja sa Japanom, gde je Srbija realizovala oko 2\% svojih kulturnih aktivnosti.

Rezultati istraživačkog uzorka pokazuju da je Srbija u proteklih deset godina samo delimično pratila svoje spoljnopolitičke principe u odnosu na kulturne aktivno-

Ministarstvo spoljnih poslova koje je ukinulo Direkciju za kulturnu naučnu prosvetnu sportsku saradnju, koja je takođe svedena na nivo odeljenja sa ograničenim opsegom delovanja. 
sti. To se pre svega odnosi na nedostatak aktivnosti u zemljama EU u kojima je imidž Srbije najslabiji, kao što su Holandija i Belgija, ali i na regionalnu saradnju u širem smislu.

\begin{tabular}{|c|c|c|c|}
\hline EVROPA & $\approx$ br.pr. & SVET & $\approx$ br.pr. \\
\hline Albanija & 28 & Azija & \\
\hline Austrija & 178 & U. Arapski emirati & 0 \\
\hline Belgija & 18 & Izrael & 27 \\
\hline Belorusija & 28 & Indija & 18 \\
\hline Bosna i Hercegovina & 60 & Indonezija & 2 \\
\hline Bugarska & 59 & Iran & 6 \\
\hline V. Britanija & 21 & Japan & 54 \\
\hline Grčka & 93 & Jordan & 2 \\
\hline Irska & 0 & Katar & 0 \\
\hline Italija & 151 & Kina & 23 \\
\hline Kipar & 9 & J. Koreja & 19 \\
\hline Litvanija & 1 & Kuvajt & 2 \\
\hline Mađarska & 38 & Liban & 2 \\
\hline Makedonija & 50 & Mjanmar & 5 \\
\hline Nemačka & 103 & Palestina & 1 \\
\hline Poljska & 70 & Sirija & 3 \\
\hline Portugal & 47 & Afrika & \\
\hline Rumunija & 66 & Alžir & 4 \\
\hline Ruska Federacija & 88 & Angola & 0 \\
\hline Skandinavija: Danska & 15 & A. Egipat & 11 \\
\hline Skandinavija: Island & 4 & Etiopija & 2 \\
\hline Skandinavija: Norveška & 47 & Južnoafrička r. & 1 \\
\hline Skandinavija: Finska & 15 & Kenija & 3 \\
\hline Skandinavija: Švedska & 42 & Maroko & 4 \\
\hline Slovačka & 45 & Tunis & 8 \\
\hline Slovenija & 40 & Severna Amerika & \\
\hline Turska & 21 & Sjedinjene a. države & 69 \\
\hline Ukrajina & 44 & Kanada & 95 \\
\hline Francuska (sa KIC) & 280 & Srednja i Južna Amerika & \\
\hline Holandija & 25 & Argentina & 6 \\
\hline Hrvatska & 86 & Brazil & 11 \\
\hline Crna Gora (od 2008.) & 5 & Kolumbija & 3 \\
\hline Češka & 41 & Kuba & 9 \\
\hline Švajcarska & 26 & Meksiko & 31 \\
\hline \multirow[t]{5}{*}{ Španija } & 34 & Paragvaj & 1 \\
\hline & & Peru & 2 \\
\hline & & Čile & 2 \\
\hline & & Australija & 35 \\
\hline & & Novi Zeland & 1 \\
\hline
\end{tabular}

Tabela 1: Broj kulturnih programa prema zemlji realizacije

Kulturni programi, kao deo kulturnih aktivnosti Srbije u Evropi i svetu, obuhvataju više oblika, vrsta i tipova, u zavisnosti od oblika kulturno-umetničke delatnosti. Zastupljenost ovih aktivnosti prema obliku kulturnih programa (Grafikon 2), pruža odgovor na pitanje koje su dominantne forme predstavljanja Srbije u Evropi i svetu u 
okviru međunarodnih kulturnih odnosa. Na osnovu istraživačkog uzorka, dobijeni su sledeći rezultati: najzastupljeniji oblik jeste izložba sa oko $27 \%$, zatim su približno jednako zastupljeni koncerti (14\%) i pozorište (13\%) kao scenski oblici, kao i filmski (13\%) i književni program $(12 \%)$, te programi koji se tiču protokola, konferencije i sl. Pojedinačno kulturne manifestacije kao npr. Dani kulture Srbije (5\%), kao i folklorne predstave (4\%) zastupljeni su u najmanjem obimu.

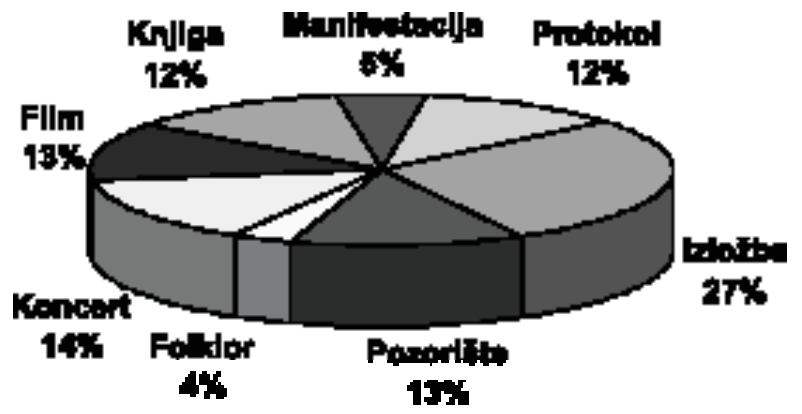

Grafikon 2: Zastupljenost programa prema obliku kulturnih programa

\section{Izložbe}

Izložba, kao oblik difuzije kulture, predstavlja najčešći i gotovo najznačajniji vid uspostavljanja kontakta i komunikacije u međunarodnim kulturnim odnosima, što se potvrđuje i na primeru Srbije.

\section{Umetničke izložbe (vizuelne umetnosti)}

- Likovne (samostalne) izložbe su najbrojnije, među kojima su dela prevashodno manje poznatih ili neafirmisanih stvaralaca. S druge strane, retrospektivne izložbe su zastupljene manjim delom, i obuhvataju dela reprezentativnih umetnika Save Šumanovića, Petra Lubarde i Milene Pavlović Barili. Ovakvim odnosom zastupljenosti najbrojnijeg tipa kulturnih programa, nameće se ideja o tzv. popunjavanju prostora, odnosno ispunjavanja okvira kulturnih delatnosti ne kvalitetom, već pre svega kvan-

\section{titetom.}

- Programske i tematske izložbe, posebno su značajne sa aspekta saradnje domaćih muzeja sa institucijama u inostranstvu. To se u najvećem broju odnosi na međunarodne izložbe, kao što su „Impresionisti“ u gradu Komo sa 
123 eksponata iz Narodnog muzeja u Beogradu; izložba „Od Karpaća do Kanaleta. Riznice italijanske umetnosti iz Narodnog muzeja u Beogradu“ u Nacionalnoj pinakoteci u Bolonji; izložba „XIV vek na Jadranu, Paolo Venecijano i slikarstvo između Istoka i Zapada“ u Riminiju, gde je Narodni muzej iz Beograda takođe učestvovao sa svojim eksponatima.

Pored toga, značajne su i izložbe srpske umetnosti, koje su rezultat saradnje domaćih i inostranih institucija kulture. Takve su, na primer, izložbe „Vek srpske umetnosti 1850-1950" iz kolekcije Narodnog muzeja u Beogradu u Nacionalnom muzeju umetnosti u Bukureštu (otvorena u prisustvu predsednika Srbije Borisa Tadića i predsednika Rumunije Trajana Baseskua); kao i izložba „O normalnosti - umetnost u Srbiji 1989-2001.“, Muzeja savremene umetnosti u Beogradu u Muzeju moderne umetnosti u Klagenfurtu (ocenjeno je kao najznačajniji kulturni projekat godine $\mathrm{u}$ tom muzeju zbog visokog kvaliteta i prestiža srpskih umetnika).

- Zajedničke izložbe i razmene izložbi, predstavljaju još jedan oblik međunarodne kulturne saradnje. To su, na primer, izložba sedmoro umetnika iz Srbije u Kulturnom centru grada Tamperea u Finskoj u okviru projekta „Mixed Worlds“; „Med i krv“ izložba mladih srpskih i grčkih umetnika, u galeriji „Booze Cooperativa“ pod pokroviteljstvom Fakulteta likovnih umetnosti u Atini i FLU u Beogradu i uz podršku Ambasade Srbije. Razmena izložbi je, prema istraživačkom uzorku, najviše zastupljena sa zemljama iz šireg regiona. Takva je bila razmena dve velike izložbe - S. Pamučkijeva u Beogradu i R.Teodosijevića u Sofiji. Značaj ovog tipa izložbi je u tome što stvaraoci ostvaruju direktan kontakt i dijalog kultura iz kojih dolaze.

- Učešće na svetskim izložbama savremene umetnosti, kao što je Bijenale u Veneciji, predstavlja i najznačajniji kulturni interdisciplinarni događaj u svetu. Imajući u vidu istorijsku političku pozadinu Bijenala, jasno je da samo prisusttvo zemalja na ovoj izložbi, nacionalni paviljoni i umetničke postavke, izražavaju ne samo vladajuće trendove u umetnosti, već i konkretne političke stavove. Za Srbiju, s obzirom na turbulentne društveno-političke događaje u protekloj deceniji, ova vrsta manifestacija jeste svojevrstan izazov, kome se pristupalo sa različitim ciljevima i interesima. Tako su na primer, na likovnom bijenalu Srbiju predstavljali umetnici Tanja Ostojić, Milica Tomić, Mrđan Bajić, dok su u ulozi komesara bili Vladimir Veličković, Branislav Dimitrijević, itd. Ovaj tip kulturnih događaja zasigurno spada u prvorazredne prilike za prezentaciju zemlje i njenih kulturnih specifičnosti. 
- Izložbe naivnog slikarstva izuzetno su zastupljene i to prevashodno Babka galerija iz Kovačice i Muzej naivne i marginalne umetnosti iz Jagodine. Ove izložbe predstavjaju naivno slikarstvo, narodnu i tradicionalnu umetnost nacionalnih manjina i etničkih grupa iz Srbije, čime se Srbija promoviše kao multikulturno društvo. Poseban aspekt važnosti ovih izložbi jeste mesto realizacije, a to su u značajnoj meri zgrade evropskih institucija (zgrada Evropskog parlamenta u Briselu, sedište UNESKO-a u Parizu, UN kompleks u Beču, itd.), što naglašava političku poruku ovih kulturnih aktivnosti Srbije.

- Izložbe o kulturnoj baštini odnose se na crkve i manastire, te freske i ikone, kao i na pravoslavno nasleđe na Balkanu uopšte. Najčešće teme izložbi su: manastiri na Kosovu, manastiri i crkve Srbije koji se nalaze na listi UNESKO svetske baštine, kao i Hilandar. Posebno je značajna izložba Narodnog muzeja u Beogradu „Srbija zemlja fresaka“ koja je bila postavljena u više zemalja u svetu. ${ }^{15}$ Tema kulturne baštine kao nezaobilaznog elementa u kulturnoj politici zemlje, a posebno njenoj međunarodnoj dimenziji, zahteva posebnu analizu, kojom bi se razmotrili najznačajniji segmenti, a najviše interpretacija značenja kulturne tradicije u okviru nacionalnog kulturnog identiteta.

\section{Kulturološko-dokumentarne izložbe}

Iako procentualno značajno manje zastupljene od umetničkih, ove izložbe predstavljaju izuzetno važan vid komunikacije i kulturnih aktivnosti Srbije u Evropi.

- Muzeološke studijske izložbe na kojima je Srbija učestvovala najvećim delom su posvećene vizantijskom nasleđu. To su, na primer, foto-dokumentarna izložba „Vizantija - kapija između Istoka i Zapada“ u Londonu (eksponate za izložbu je dalo 16 zemalja, među kojima i Srbija); izložba „Balkan. Antička civilizacija između Dunava i Jadrana“, sa preko 250 eksponata iz arheološke zbirke Narodnog muzeja iz Beograda u okviru Nacionalnog muzeja u Adriji, izložba „Vizantija - raskoš

15 Iz saopštenja Ministarstva kulture povodom izložbe: „Kao materijalna svedočanstva o autohtonosti srpske kulture i specifičnog vizuelnog izraza srpske srednjovekovne duhovnosti, freske i kamena plastika predstavljaju kod za razumevanje srpske duhovnosti i kulture, a danas, osim religijskog aspekta, one su ujedno i oličenje srpskog kulturnog identiteta, navedeno je u saopštenju Ministarstva kulture. Izložba je sastavni deo aktivnosti Ministarstva kulture koje imaju za cilj da predstave srpsku kulturu i kulturno nasleđe na međunarodnom planu, čineći je što vidljivijom i gradeći svest međunarodne javnosti o našem kulturnom identitetu i vrednostima.“ www.kultura.gov.rs 
i svakodnevni život" u Umetničkoj izložbenoj galeriji u Bonu, pored eksponata iz Istanbula, Ravene, Efesa i drugih gradova, predstavljeno je 60 predmeta sa lokaliteta Caričin grad, iz fundusa Narodnog muzeja u Leskovcu. Ove izložbe ukazuju na mesto vizantijskog nasleđa u sagledavanju ukupnog kulturnog nasleđa Srbije i njegove afirmacije putem prioriteta kulturne politike.

- Sociokulturne (kulturološke u užem smislu) izložbe

Primer „Srbija - kulturna spona Istoka i Zapada“ u Muzeju katedrale Svetog Stefana u Beču, pod visokim pokroviteljstvom predsednika Srbije i Austrije, Borisa Tadića i Hajnca Fišera, u organizaciji Matice srpske, bavi se srpskim kulturnim nasleđem, kao i istorijom Srbije u poslednjih 12 vekova, prati razvojni put od vizantijskog perioda, preko turskog uticaja do preuzimanja vrednosti zapadnoevropske kulture, naročito od 18. veka. Drugi primer je izložba „Dva Radoslava, dva vremena“ Narodne biblioteke Srbije koja je postavljena u više zemalja sveta, a predstavlja dve paralelne priče koje opisuju dva razdoblja istorije života u Srbiji, srednjovekovnoj i onoj u prvoj polovini 20. veka. Ove izložbe reprezentativnog tipa mogu se smatrati projektima od nacionalnog značaja $\mathrm{u}$ tome što tretiraju prevashodno istoriju Srbije kao najdelikatniju odrednicu identiteta u pravcu njenog boljeg

razumevanja i prevazilaženja predrasuda.

- Monografske izložbe o značajnim ličnostima iz Srbije, obuhvataju uglavnom one koji su već poznati određenom delu međunarodne javnosti, kao što je Nikola Tesla, ali kao što su i književnici: Ivo Andrić, Danilo Kiš, Borislav Pekić, Jovan Jovanović Zmaj, itd. Iako zbirno gledano ove vrste izdvajanja najznačajnijih ličnosti može odvesti prevelikom pojednostavljivanju, pa i diskriminaciji, važno bi bilo sagledati, bar na nivou dostignuća u određenim oblastima stvaralaštva, koje ličnosti zaslužuju ovu vrstu međunarodne pažnje i afirmacije.

\section{Propagandno-animacione izložbe}

Privredne izložbe i sajmovi su vrsta događaja na kojima se predstavlja ono što je autentičnost zemlje u smislu proizvoda nastalih kao deo tradicije, običaja, kulturne baštine i sl. Takve su na primer, etno izložbe, kao deo manifestacija o kulturama zemalja, a u istraživačkom uzorku izložba pirotskih ćilima bila je najzastupljenija.

- Izložbe o kulturnom turizmu za Srbiju su nekoliko godina unazad postale značajne prilike za promociju programa kao što su „Put rimskih imperatora“, „Tvrđave na Dunavu“ i „Transromanika“. Na taj način teme koje se 
tiču kulture sećanja i interkulturnog dijaloga, kao i zaštite kulturnog nasleđa dolaze $u$ fokus potencijalnog interesovanja u međunarodnom kontekstu.

- Svetske mega izložbe kao što je EXPO posebna su prilika za višestrano predstavljanje zemlje i svojevrstan kontakt sa kulturama koje su inače geografski udaljene. Samostalni nastup Srbije prvi put je bio na EXPO izložbi u Šangaju 2010. godine, dok 2000. godine na milenijumskoj EXPO izložbi u Hanoveru Srbija nije učestvovala (iako su to učinile pojedine zemlje iz regiona). Najveći izazov ove manifestacije jeste masovna posećenost i vidljivost na mapi sveta, koja bi trebalo da pokaže mesto zemalja iz ugla inovacije, kreativnosti, ali i autentičnih vrednosti i kulturnog identiteta.

\section{Scenski programi}

Prema navedenoj tipologiji, scenskim programima su obuhvaćene predstave (u okviru kojih su najzastupljenije pozorišne dramske predstave) i koncerti (od klasične do popularne i etno muzike).

\section{Predstava}

- Pozorišna dramska predstava

Najviše su zastupljeni domaći savremeni autori (oko 50\% svih pozorišnih predstava), a najizvođeniji su komadi Biljane Srbljanović i Dušana Kovačevića, koji u politički angažovanom i kritičkom ključu stvaraju slike društvene stvarnosti i tekućeg života Srbije. Od domaćih „klasika“ najzastupljenije su predstave prema komedijama Nušića i Sterije. U znatno manjem obimu svoja gostovanja imale su predstave dela stranih autora.

- Muzičke i plesne predstave (opera, balet i savremeni ples)

U okviru kulturnih aktivnosti Srbije, i u datom istraživačkom uzorku, reč je pre svega o predstavama opere i baleta Narodnog pozorišta iz Beograda, koje su gostovale u evropskim gradovima. Savremeni ples nije u tom kontekstu postigao vidljivost, iako ova oblast umetničkog delovanja ima aktivnu međunarodnu saradnju, uglavnom putem umetničkih mreža i direktnih koprodukcija.

\section{- Folklorna predstava}

U odnosu na ostale vrste scenskih kulturnih programa (Grafikon 2), zastupljenost folklornih predstava vodećih 
ansambala („Kolo“, „Lola“, „Branko Krsmanović“, itd.) ukazuje na značaj ove vrste kulturno-umetničkog delovanja u kulturnim aktivnostima Srbije u Evropi i svetu. Ovi programi narodnih igara i pesama predstavljaju opšta mesta vezana za tradiciju, karakter i običaje naroda ne samo Srbije već iz celog regiona.

\section{Koncert}

- Koncerti klasične muzike su najzastupljeniji, posebno u formi solističkih koncerata afirmisanih kao i manje poznatih umetnika. Najveći broj nastupa u protekloj deceniji imali su Gudači Sv. Đorđa, u čijem repertoaru su zastupljena dela domaćih kompozitora.

- Horski koncerti su takođe izuzetno zastupljeni, najčešće putem učešća na festivalima i takmičenjima. To se posebno odnosi na hor Beogradski madrigalisti, sa opsežnim repertoarom duhovne muzike.

- Koncerti popularne muzike, u konkretnom slučaju vezuju se za ličnosti sa najvećom popularnošću i najmasovnijom publikom, a to su: Goran Bregović sa Orkestrom za svadbe i sahrane i Emir Kusturica sa No Smoking Orchestra. Ovi umetnici su svojim nastupima zadobili ne samo popularnost širom sveta, već i titule počasnih građana u metropolama poput Buenos Airesa.

- Koncerti etno muzike zastupljeni su u znatno manjoj meri, a umetnici koji se spominju u tom kontekstu su Bora Dugić, Biljana Krstić i Boban Marković.

Generalno, scenski programi su od svih kulturnih aktivnosti Srbije i najjednostavniji u smislu tumačenja značenja, ali i mehanizma selekcije. Uz to, jasno je da se u najvećem broju programa radi zapravo o samostalnim aktivnostima institucija i pojedinaca, koji u formi gostovanja i turneja obavljaju sopstveni način međunarodne kulturne saradnje.

\section{Filmski programi}

- Učešće na međunarodnim filmskim festivalima, kao deo kulturnih aktivnosti Srbije, zastupljeno je samo delimično i uslovljeno je ukupnom godišnjom produkcijom. U proseku su filmovi Gorana Paskaljevića u datom periodu učestvovali na najvećem broju festivala, dok su najviše nagrađivani filmovi Srdana Golubovića (,Apsolutnih sto“, „Klopka“). 
- Regionalni festivali (balkanski film, filmovi Jugoistočne Evrope, i sl.) po svojoj koncepciji se razlikuju, ali je zajedničko da prikazuju filmove mlađih reditelja, kao i dokumentarne i kratkometražne filmove.

- Revije i projekcije filmova srpske produkcije mogu se razvrstati u manifestacije posvećene novom srpskom fil$\mathrm{mu}$, koje su i najbrojnije, i revije posvećene ranom srpskom filmu. Ovi programi se odnose pre svega na savremenu filmsku produkciju, kao i na filmove koji su postali svojevrsni „klasici“ srpske kinematografije.

- Fenomen Kusturica je poseban element ne samo u domenu filmskog stvaralaštva, već i sa aspekta ukupnog

kulturnog, pa i političkog delanja ovog stvaraoca.

Zbirno gledano, kinematografija Srbije u kontekstu kulturnih aktivnosti u inostranstvu ima značaja samo sa aspekta pojedinačnih filmskih ostvarenja, i još više njihovih autora.

\section{Književni program}

Domen književnosti i izdavaštva jedan je od perspektivnijih sa aspekta kulturnih aktivnosti u međunarodnom okruženju, iako to može delovati paradoksalno, pre svega zbog jezičkih barijera. Da je knjiga put do pravog dijaloga, pokazuje i niz ostvarenih programa, kao i prevodilačkih poduhvata.

- Prevod knjige je najzastupljenija forma aktivnosti koja se tiče književnosti. U proteklih deset godina, najviše je prevedeno dela Danila Kiša, a zatim Ive Andrića, Miloša Crnjanskog, Vaska Pope, Milorada Pavića i Vide Ognjenović. Uz to, prevođene su antologije pesništva i savremene srpske drame.

- Književno veče je najčešće posvećeno jednom savremenom književniku - gostu. Međutim, iako malobrojne, značajne su književne večeri koje obuhvataju književnost Srbije u jednom širem kontekstu. Takve su na primer: literarno veče pod naslovom „Tragični identitet Evrope - književnost iz Srbije“ u organizaciji Instituta za slavistiku Univerziteta u Beču, Ambasade RS i uz podršku Kulturkontakta u Literaturhausu, domu književnika u Beču; i književno veče „Srpska književnost i Evropa“ u Ambasadi RS u Atini, u saradnji sa Ministarstvom kulture RS.

Takođe, značajne su i književne večeri koje na poseban način približavaju Srbiju sa drugim kulturama: „Književne veze između danske i srpske kulture" u Ambasadi RS 
u Kopenhagenu, na kome su učestvovali prevodioci, pisci i profesori slavistike, kao i poetsko veče „Putovanje kroz srpsku i indijsku poeziju“ $u$ rezidenciji ambasadora Srbije u Nju Delhiju.

- Učešće na međunarodnim sajmovima knjiga obeleženo je nastupima Ministarstva kulture Srbije sa nacionalnim štandom u Lajpcigu, Frankfurtu, Solunu i Beču, na kojima su predstavljeni književnici i izdavači iz Srbije, sa prosečno 400 naslova.

Navedene ličnosti, teme i povodi potvrđuju tezu o značajnom potencijalu Srbije u domenu knjige i izdavaštva, posebno prema regionalnom i evropskom okruženju.

\section{VManifestacija}

Iako se jedan deo već analiziranih kulturnih aktivnosti Srbije može podvesti u grupu manifestacija, ovde su izdvojeni specifični oblici ovog vida kulturnih delatnosti.

- Dani kulture, kao specifičan vid kulturne saradnje, najčešće su uzvratnog tipa, ali se takođe vezuju i za dijasporu. Tako je Srbija realizovala najveći broj programa ove vrste u zemljama u kojima su inače najintenzivnije kulturne aktivnosti (Tabela 1): od evropskih zemalja Austrija, Nemačka i Francuska, u širem regionu Hrvatska i Rumunija, a od ostalih zemalja u svetu Kanada i Australija.

- Na manifestacijama posvećenim Balkanu, najčešće u formi festivala, Srbija je bila predstavljena kroz različite programe: na „Balkan Trafic“ festivalu u Briselu učestvovali su trubački orkestar Dejana Lazarevića, filmovi Gorana Markovića, ansambl „Kolo“ i instrumentalista Bora Dugić; u programu „Zapadni Balkan u kulturnom fokusu“, u organizaciji Austrijskog kulturnog foruma u Londonu, učestvovali su i umetnici iz Srbije: likovni umetnik Dragan Đorđević, hor „Horkeškart“, muzička grupa „Kal“" i reditelj Želimir Žilnik; kao i trodnevna svečanost u Atini posvećena kulturi na Balkanu, u organizaciji Helenske fondacije za kulturu i pod pokroviteljstvom predsednika Republike Grčke K. Papuljasa, učestvovali orkestar Narodnog pozorišta iz Beograda, eksponati Muzeja savremene umetnosti iz Beograda, tridesetak srpskih proznih autora, akademik Ljubomir Simović, itd.

- Prigodne manifestacije su u manjem broju organizovane različitim povodima, na primer: centralna proslava povodom 200 godina Prvog srpskog ustanka i stvaranja srpske moderne države u Torontu, obeležavanje 60. go- 
dišnjice uspostavljanja diplomatskih odnosa sa Meksikom, itd.

$\mathrm{U}$ analiziranom uzorku, prepoznaje se tendencija koja sve više ide u pravcu određenog profilisanja i onih manifestacija opšteg tipa. U tom smislu, sve veći broj festivala i manifestacija koje su posvećene kulturama Balkana može biti indikator za definisanje konceptualnog okvira nekih kulturnih programa Srbije.

\section{Konferencija. Radni sastanak.}

Konferencije i radni sastanci vezuju se za protokolarni deo kulturnih aktivnosti Srbije, koji se odnose na kreatore kulturne politike, rukovodioce institucija kulture, stručnjake u kulturi i sl. Iz tog razloga je važno napomenuti koje su teme i događaji najviše zastupljeni u kontekstu učešća predstavnika Srbije. Na primer, to su: učešće predstavnika Ministarstva kulture R Srbije na konferenciji ministara kulture 23 zemlje Centralne, Istočne i Jugoistočne Evrope u Gracu, pod nazivom „Kreativna Evropa - novo partnerstvo“; učešće ministra kulture Srbije D. Kojadinovića na međunarodnoj konferenciji „Inclusive Europe? Horizon 2020“ u Budimpešti, u organizaciji Ministarstva za kulturno nasleđe RM i Evropskog foruma za umetnost i nasleđe; učešće Sretena Ugričića, direktora Narodne biblioteke Srbije na konferenciji o ulozi umetnosti i kulture u evrointegraciji Balkana, u Hagu u organizaciji Evropske kulturne fondacije; učešće ministra kulture Srbije N. Bradića na Konferenciji Crnomorske inicijative „Saradnja kao odlučujuće sredstvo za održivi razvoj kulturnog turizma“ u Tirani. Od stručnih skupova na kojima su učestvovali predstavnici Srbije, najzastupljeniji su oni posvećeni zaštiti kulturnog nasleđa. Ovo dodatno ukazuje na prioritete kulturne politike Srbije, kao i na potrebu za njihovom jasnijom sistematizacijom.

\section{Zaključna razmatranja}

Na osnovu analize kulturnih programa, koji čine okosnicu kulturnih aktivnosti Srbije u Evropi i svetu, u periodu od 2000. do 2010. godine, moguće je izvesti neke opšte zaključke, koji se tiču sadržaja i politike kreiranja ovih programa. Dakle, sadržaj čine raznovrsni programi koji su uglavnom proizvodi elitne kulture, a manjim delom sadržaji popularne kulture. U takvom skupu nisu sasvim 
jasno koji su dominantni narativi. Pre se može govoriti o nedostatku artikulisanih narativa u odnosu na postojeće kulturne vrednosti. Na analiziranim kulturnim programima Srbije uočljiva je podeljenost srpske kulturne matrice između evropskog i tradicionalnog identiteta. To ukazuje na prisustvo dihotomija evropeizacije i novih vrednosti sa jedne strane i tradicija izraženih u hrišćanstvu i vizantijskom nasleđu sa druge strane.

Zaključak je da Srbija u nedovoljnoj meri, nesistematično, partikularno i uglavnom reaktivno pristupa kulturnim aktivnostima kao delu međunarodne dimenzije svoje kulturne politike. To znači i da međunarodni kulturni odnosi nisu jasan prioritet Srbije.

Potreban je novi pristup u razvijanju strategija i programa kulturne politike, koji će pored afirmacije nacionalnog kulturnog identiteta, afirmisati i one vrednosti i programe koji predstavljaju izraz kulturne raznolikosti cele teritorije zemlje. Da bi ovakav pristup bio moguć, važno je, između ostalog, napustiti sektorski pristup koji proizvodi kratkoročne rezultate. Potrebno je uobličiti strategiju na način da se fokusira komunikacija i da se ona usmeri ka konsenzusu koji može podržati nameravanu akciju. Ovo ubličavanje strategije uključuje svesni pokušaj da se rekonstruiše kontekst, odnosno da se debata postavi u novi okvir. To znači da je potrebno uneti nove sadržaje, s obzirom da je novi narativ ujedno i način da se uvedu novi ,glasovi u raspravi“ i način da se pomire tradicionalne vrednosti, etničke emocije i mitovi sa novim kulturnim i građanskim vrednostima. Na kraju, postavlja se pitanje kakve su mogućnosti na raspolaganju za kreiranje suštinski novog koncepta, te ko bi bili nosioci takvog poduhvata? U aktuelnom stanju izuzetno smanjenog interesovanja države za pitanja kulture, čini se, da je za Srbiju od velikog značaja redefinisanje interesa države, što se odnosi i na odnos prema sistemu vrednosti (kulturnom obrascu), i prema nacionalnom kulturnom identitetu i prema prioritetima u međunarodnim kulturnim odnosima uopšte. U međuvremenu, inicijativa, pa i odgovornost za kulturne akcije Srbije u Evropi i svetu ostaju na umetnicima i kulturnim radnicima, da osmisle ili bar popune, iskazane i neiskazane principe državne kulturne politike, a sve u očekivanju konstituisanja novog kulturnog sistema Srbije. To bi ujedno bio i jedan od načina za prevazilaženje efekata pomenutih dihotomija i za ispunjenjem društvenog i kulturološkog okvira vrednosti, koje se nalaze negde između Egzita i Guče. 


\title{
LJILJANA ROGAČ
}

\section{LITERATURA:}

Berelson B., Content Analysis in Communication Research, Hafner Publishing Company, New York 1971.

Božović R., Život kulture, „Filip Višnjić“, Beograd 2009, str. 29.

Dragićević Šešić M., „Demokratičnost i dometi kulturne politike“, Zbornik Fakulteta dramskih umetnosti, br. 8-9, Beograd 2004-2005, str. 387-397.

Dragićević Šešić M. Stojković B., Kultura menadžment animacija marketing, CLIO, Beograd 2007.

Đukić Dojčinović V., Tranzicione kulturne politike - konfuzije i dileme, Zadužbina Andrejević, Beograd 2003.

Đukić V., Država i kultura - studije savremene kulturne politike, Institut za pozorište, radio i televiziju, Fakultet dramskih umetnosti, Beograd 2010.

Golubović Z., „Kulture u tranziciji u Istočnoj Evropi i Jugoslaviji: raskorak između kulturnog i nacionalnog obrasca“, u: Kulture u tranziciji, Plato, Beograd 1994.

Golubović Z., Pouke i dileme minulog veka, „Filip Višnjić“, Beograd 2006.

Majnhof U.H., Triandafilidu A. (prir.), Transkulturna Evropa, CLIO, Beograd 2008.

Rogač Lj., „Kulturna dijagnostika identiteta i imidža Srbije u evropskom kontekstu“, u: Kultura, br. 122/123, Beograd 2009, str. 120-140.

Vizomirski Dž. M., Šnajder P. S., Kulturna diplomatija, Balkankult fondacija, Beograd 2006.

Ljiljana Rogač

Belgrade University of Art, Faculty of Drama Arts

\section{CULTURAL ACTIVITIES OF SERBIA IN EUROPE AND WORLD: 2000-2010}

\begin{abstract}
The introductory text comments on the relevance of cultural values and cultural relations in the context of the changed global environment and actors in the international arena. Particularly noteworthy is the importance of content quality and effective narratives in cultural relations. The text continues to emphasize the socio-political aspects that have shaped the cultural development of Serbia at the beginning of the $21^{\text {st }}$ century. The review of basic research results of ,Serbian Cultural activities in Europe and worldwide from 2000 to $2010^{\text {" form a major part }}$ of the text and present a contribution to the wider analysis of international cultural relations of Serbia. The research questions are related to the content of the cultural activities of Serbia, then the ideas, values and narratives, and finally to the principles and priorities of cultural policy in the context of international cultural relations.
\end{abstract}

Key words: Serbia, cultural policy, international cultural relations, cultural pattern, cultural programme 